\title{
LEER E INTERPRETAR LA IMAGEN PARA TRADUCIR
}

\section{READING AND INTERPRETING IMAGES FOR TRANSLATING}

\section{José Yuste Frías*}

\section{RESUMEN}

Desde la noción de paratraducción como fundamento traductológico, la imagen puede ser considerada en traducción como un paratexto icónico cuya lectura e interpretación simbólicasrequieren de una cierta disciplina metodológica paratraductiva a la hora de cultivar el sentido de la mirada del traductor.A través de dos corpus diferentes, por una lado, las imágenes dibujadas de unos supuestos «pictogramas» de la Xunta de Galicia y, por otro, las «nuevas caras» de los estuches de Kinder Chocolate, José Yuste Frías demuestra en este artículo que la imagen en traducción no es universal. La manipulación de la imagen, conlleva no sólo implicaciones simbólicas, sino también, ideológicas, políticas, sociales y culturales que influyen enormemente en la presentación final de los productos de la traducción.

Palabras Clave: imagen, símbolo, colores, paratextualidad, paratraducción, publicidad, TISP

\section{ABSTRACT:}

From the translatological standpoint of paratranslation, images can ben considered in translation as iconic paratexts whose symbolic reading and interpretation call for a certain methodological and paratranslational discipline regarding the creation and development of the translator's perspective. Based on two different corpora, -on the one hand the sketchs of would-be "pictograms" by Xunta de Galicia, on the other, the "new faces" of Kinder Chocolate boxes- José Yuste Frías shows in this paper that images in translation are not universal. Manipulation of images entails not only symbolic implications, but also ideological, political, social and cultural questions that have a key import in the final presentation of the products of translation.

Keywords: image, symbol, colours, paratextuality, paratranslation, advertising, PSTI

El traductor siempre ha vivido en el mundo de la imagen. Incluso en un encargo de un texto sin imagen, el traductor no traduce lenguas ni palabras a palo seco, como si fuera un programa de traducción automática, sino que lo que le diferencia de las máquinas es, precisamente, su capacidad para traducir imaginarios vehiculados por las imágenes mentales implícitas en el texto. Las imágenes

*. Universidade de Vigo, Vigo (Galícia), Espanha. jyuste@uvigo.es 
«mentales»son representaciones mentales que se elaboran gracias a la lectura de un texto y un escáner no «lee» un texto, simplemente «reconoce ópticamente los caracteres».

Pero, además de las imágenes «mentales», cerca del texto, al lado del texto, junto al texto, en el texto y entre el texto están las imágenes materializadas en los paratextos icónicos que, conformando entidades iconotextuales, contribuyen también a crear determinados imaginarios. No se puede traducir ninguna unidad verbal si previamente no se ha leído e interpretado todas y cada una de las unidades icónicas que rodean, envuelven, acompañan, prolongan, introducen y presentan las unidades verbales tanto en papel (traducción publicitaria; traducción de cómics; traducción técnica; traducción de libros infantiles, libros ilustrados y libros de arte, etc.) como en pantalla (doblaje; subtitulado; localización de productos multimedia; traducción de libros electrónicos; traducción de sitios web; traducción de videojuegos; etc.). En el actual y digital mercado profesional de la traducción, asistimos a una proliferación sin precedentes de dichas imágenes «materiales» cada día más manipulables.

\section{OMNIPRESENCIA DE LA IMAGEN EN LA ERA DIGITAL}

Muy lejos de ser algo indiferente, el nuevo soporte digital del texto ha modificado sustancialmente, los procesos y los productos de la traducción. Dado que el texto digital puede tomar una gran variedad de formas en pantalla, enfocadas todas hacia la interactividad con el destinatario final, la actividad del lector de una traducción en la era digital viene marcada por cualquier mínimo detalle visual que el traductor haya sabido leer e interpretar en todos y cada uno de los paratextos icónicos del texto de partida.

Hoy en día resulta difícil encontrar un texto en pantalla donde no aparezcan destellos de iconos, colores e imágenes fijas o animadas acompañando, rodeando y envolviendo en pantalla al texto que se encarga traducir. Todos estos componentes de la comunicación visual deben ser leídos e interpretados adecuadamente para traducir correctamente en la era digital. Así, por ejemplo, para que los destinatarios finales de un encargo de traducción de una web naveguen eficazmente en las distintas páginas del sitio web, una vez traducido, el profesional de la traducción debe saber, en todo momento, qué valor simbólico se le ha otorgado a cada imagen en la web de partida para traducir el mismo valor simbólico (con la misma imagen u otra) en la web de llegada. Sólo así, se podrá lograr orientar al usuario de la lengua y cultura de llegada y provocar que pinche sobre cada imagen hipervinculada. 
Cuando se realizan encargos de traducción para la pantalla (Screen Translation) la paratextualidad se convierte en la categoría principal de las cinco categorías transtextuales definidas por Genette (1987). En efecto, la imagen «material», el paratexto icónico, no sólo es una parte integrante del texto en pantalla (peritexto icónico) sino que juega un papel esencial en el entorno digital en el cual el texto es leído e interpretado gracias a un soporte informático que sitúa siempre al traductor no sólo «delante» sino también «dentro» de la pantalla, máxime cuando se trata de videojuegos u otros espacios virtuales de información o entretenimiento. Los peritextos icónicos aparecen a menudo en pantalla asociados a diferentes acciones en los videojuegos y en las páginas web: un icono permite hacer desfilar el texto; otro permite encontrar una palabra que se buscaba; un icono permite ir hacia atrás, otro hacia adelante; hay iconos que permiten aumentar o disminuir una imagen a nuestro antojo; algunos iconos permiten escuchar música, otros ver un fragmento de una película; sin olvidar todos los iconos que permiten al usuario desplazarse por el espacio virtual del videojuego o de la web.

El traductor no puede dejar de ocuparse de todas estas producciones paratextuales que, en pantalla, rodean, envuelven, acompañan el texto y, fuera de la pantalla, lo prolongan. Todos estos elementos paratextuales introducen y presentan al texto de una forma u otra. Traducir en la era digital, implica empezar a plantearse, muy seriamente, que las nuevas producciones paratextuales presentes en los nuevos espacios de escritura para la pantalla exigen una nueva forma de traducir: la paratraducción ${ }^{1}$.

\section{DE LA PARATEXTUALIDAD A LA PARATRADUCCIÓN}

El estudio pormenorizado de las entidades iconotextuales, el mínimo análisis de las producciones verbales, icónicas y verbo-icónicas o la simple constatación de las producciones materiales de los paratextos que rodean, envuelven, acompañan, prolongan, introducen y presentan el texto de un encargo de traducción impuso la creación del nuevo concepto de paratraducción. Necesitábamos un nuevo término traductológico para llamar la atención sobre la traducción de lo que, hasta ahora, se había quedado en un segundo plano en los estudios sobre traducción: los paratextos.

1. Para comprobar la aplicación práctica del concepto de paratraducción a la hora de leer e interpretar la imagen en traducción, tanto en pantalla como en papel, véanse la conferencia y el debate que presentan el concepto clave de la Escuela de Vigo con motivo de la celebración del II Coloquio Internacional de Vigo sobre Paratraducción: Yuste-Frías, 2009a y 2009b. 
Al ocuparse de la traducción de los paratextos, la paratraducción introduce y presenta la traducción, es, de hecho, lo que permite que una traducción se presente como tal en el mundo editorial tanto en papel como en pantalla. Se trata de un nuevo término traductológico que he creado en la Universidade de Vigo (Cf. Yuste Frías, 2005: 75-82) y que ha contribuido tanto a la fundación del Grupo de Investigación TRAdUCCIÓN \& PARATRADUCCIÓN (T\&P)² como a la puesta en marcha del Máster de Investigación que lleva el mismo nombre que el Grupo T\&P. Si, como decía Gérard Genette (1987: 9-10), no puede existir texto sin paratexto, tampoco puede existir traducción sin su correspondiente paratraducción. Traducción y paratraducción son siempre inseparables, de ahí que a la hora de unir las dos nociones para dar nombre al Grupo de Investigación de Referencia (TI4) que dirijo en la Universidade de Vigo, estamos empleando no la conjunción copulativa «y» sino el signo llamado et en español, esperluette en francés, ampersand en inglés: [\&]. Esta grafía moderna del bigrama latino «et» no es propiamente hablando ni una «letra» del alfabeto ni un signo de puntuación sino todo un ideograma del trazado original de un lazo, de un nudo, de un dibujo, de una cuerda que se anuda: una ligadura. En el Grupo T\&P escribimos el signo «\&» para representar todo ese sentido simbólico de unión que deseamos que exista siempre entre la traducción y la paratraducción.

Desde un principio, la noción de paratraducción fue acuñada para analizar el espacio y el tiempo de traducción de todo paratexto que rodea, envuelve, acompaña, prolonga, introduce y presenta el texto traducido con el fin de asegurar su existencia, su recepción y su consumo en el mundo editorial no solamente bajo la forma de libro, sino también bajo cualquier otra forma de producción editorial digitalizada (libro electrónico, CD-ROM, DVD, Sitios Web, Videojuegos, etc.). En la era digital de la información los profesionales de la traducción somos cada día más conscientes de que la concepción y regulación de sentido de cualquier texto varía en función de sus paratextos, es decir, en función de un determinado conjunto de unidades verbales, icónicas, entidades iconotextuales o diferentes producciones materiales que, dentro del espacio material del texto, lo rodean, envuelven o acompañan (los peritextos) y, fuera del espacio material del texto, hacen referencia a él prolongándolo en otros espacios externos físicos y sociales virtualmente ilimitados (los epitextos).

La paratraducción permite informar sobre las actividades presentes «en el umbral de la traducción»-au seuil de la traduction (Cf. Yuste Frías, 2010b) - a la hora

2. Para más información sobre el Grupo T\&P, creado en marzo de 2005, visítese nuestro nuevo sitio web: <http://www.paratraduccion.com $>$ 
de establecer el papel de las relaciones de poder desempeñado por las distintas ideologías en la difusión y recepción de las traducciones. La paratraducción invita al traductor (sujeto que traduce y primer agente paratraductor) a leer, interpretar y paratraducir todo símbolo y toda imagen que rodea, envuelve, acompaña, prolonga, introduce y presenta al texto en los márgenes del papel o de la pantalla, en los umbrales de la traducción.

La paratraducción es un lugar periférico donde se impone la imagen mezclando dos series de códigos: el código social como discurso publicitario y los códigos productores y reguladores del sentido. Los paratextos son fenómenos de naturaleza social y antropológica que participan, junto al texto, en la construcción del sentido de la obra editada. Lejos de ser un dato tangible, el sentido en traducción es siempre el producto de la actividad de comprensión, interpretación y expresión del traductor y, por consiguiente, sólo podrá existir en la traducción editada si al sujeto que lee, interpreta y traduce no se le escapa el más mínimo detalle simbólico o icónico presente en la paratextualidad del encargo de traducción.

El concepto de paratraducción otorga a la imagen y a todo el aspecto visual de los paratextos la importancia que tienen en la construcción de sentido simbólico en traducción. Si queremos que la traducción tenga un largo porvenir en la era digital, necesitamos cuidar al máximo la imagen publicitaria de su presentación editorial tanto en papel como en pantalla, desde el peritexto de la cubierta del libro hasta el epitexto de la carátula del DVD o del videojuego, pasando por los epitextos materiales de carteles, marcapáginas, pegatinas y stands que publicitan la traducción como producto en las estanterías de las librerías. Si la traducción no se vende, nunca podrá existir porque nadie la comprará y, por consiguiente, nadie la leerá. La paratraducción de una traducción es su imagen publicitaria. L'image semble s'imposer à quiconque a affaire au paratexte (Genette, 1987: 8. Nota 1).

La importancia paratextual de la imagen resulta ser tan esencial en la comunicación traductora de la era digital que hasta los textos sin ningún tipo de imagen material son traducidos teniendo en cuenta parámetros de comunicación visual, esenciales para su edición definitiva en pantalla. Así, por ejemplo, la imagen del tipo de letra con el que se ha editado el texto de partida es tenida muy en cuenta a la hora de saber elegir si convendrá o no a la imagen del tipo de letra que la cultura ortotipográfica de llegada otorgará finalmente en la edición digital. El texto sin imágenes se convierte en un material visual más. En definitiva, la suma importancia paratextual de la especificidad de la imagen y todo lo que implica como proceso de comunicación visual en la era digital, es decir, la preponderancia de lo no verbal frente a lo verbal, impone inexorablemente la necesidad de una sólida formación universitaria en la lectura e interpretación de la imagen en traducción. 


\section{LA IMAGEN NO ES UNIVERSAL Y SUS COLORES TODAVÍA MENOS}

Todo texto invita siempre a la lectura porque sin ella no existe, en cambio una imagen que no forme parte de un encargo de traducción puede simplemente limitarse a estar ahí sin provocar lectura alguna y puede incluso que nunca nadie la interprete. La realidad demuestra que un individuo puede pasarse toda su vida viendo la misma imagen en los entornos más familiares de su espacio vital (su ciudad, su calle, su casa) sin prestarle la más mínima atención, hasta que llega el día en que deja de «ver» y empieza a «mirar» esa imagen que le había acompañado a lo largo de tantos años porque, de repente, se impone la necesidad de traducirla. Mirar implica un principio de lectura y, por consiguiente, un inicio de interpretación. Al transformar todo lo visible en legible, la traducción provoca la lectura e interpretación de la imagen.

Si el título de esta publicación plantea la traducción de la imagen es porque, al contrario de lo que suele pensarse, la imagen no es universal. En efecto, la percepción de una imagen material no es un acto universal, tal y como he demostrado en papel (Yuste Frías, 2008a) y en pantalla (Yuste Frías, 2008b y 2010a) a propósito de la percepción de una imagen publicitaria que todo el mundo cree conocer porque la ve todos los días pero nunca la había mirado (leído) e interpretado para traducir: el logotipo de Carrefour (Cf. Yuste Frías, 2008a: 153 et sqq). En efecto, la imagen del logotipo Carrefour puede provocar diferentes lecturas e interpretaciones según la cultura de llegada donde se implanta dicho logotipo. Especial mención merece el tratamiento de tres aspectos puntuales de la imagen del logotipo Carrefour según la paratraducción del paratexto icónico localizada en zonas culturales diferentes: las flechas convertidas en alabardas en Francia y en el personaje publicitario de $\mathrm{O}$ Precinbo en Brasil (Yuste Frías, 2011b); los implícitos colores de la bandera nacional en Francia y la explícita declinación de la simbología del color rojo en Japón (Yuste Frías, 2011c); y, finalmente, la letra «C» velada durante décadas en Francia y siempre desvelada en España (Yuste Frías, 2011d).

Las imágenes materiales son productos culturales cuyo sentido cambia según la localización espacio-temporal. Para comprender la información aportada por una imagen hay que compartir los mismos códigos semióticos y culturales que el público a quien va dirigida, lo cual implica, en el caso de todo profesional de la traducción, poseer las competencias culturales suficientes sobre la historia y los valores sociales de la cultura de partida donde ha sido creada la imagen y de la cultura de llegada para la cual se traduce. De lo contrario, el sentido de la imagen no sólo no será leído correctamente sino que su interpretación podrá estar llena de errores. Es el caso de los gestos que casi nunca se traducen de una lengua a otra, de una cultura a otra, lo 
cual origina una serie de errores de interpretación para los lectores-espectadores de la obra en la cultura meta. Como todavía se sigue creyendo que la imagen de un gesto no es más que un dato visual más que no tiene por qué interesar al proceso de la traducción, un gesto tan anodino para un francés como es levantar el dedo pulgar para significar una pausa en el juego puede adquirir un sentido muy diferente en otras culturas porque editores y traductores se empeñan, una y otra vez, en dejarlo de lado en todas las traducciones editadas de Astérix en Hispanie (Cf. Yuste Frías, 2011a).

Una mínima incursión investigadora de la imagen en traducción revela sin ambages que hasta los propios colores de las imágenes no son universales. Un traductor no sólo «ve» los colores de una imagen, sino que al «mirar» la imagen percibe los colores de una manera muy determinada según la lengua, la cultura, el momento y el lugar del contexto comunicativo del documento de partida, por un lado, y del documento de llegada, por otro. La percepción nunca es simple visión porque toda percepción implica siempre poner en juego el conocimiento, la memoria, la imaginación y el medio cultural tanto del documento que se encarga de traducir como del sujeto que traduce. Porque cada sociedad tiene su propia percepción diferente de los colores, han existido, existen y existirán sociedades donde se ve el color y el contraste entre colores de manera diferente. Nombrar, designar y connotar los colores no son sólo hechos lingüísticos que cambian de una lengua a otra, sino que son también hechos sociales, culturales e imaginarios diferentes según la localización espacio-temporal.

\footnotetext{
La manera de distinguir, segmentar, organizar los colores cambia de cultura a cultura. Aunque se han identificado algunas constantes transculturales, parece cuando menos difícil traducir términos de color entre lenguas alejadas en el tiempo o de civilizaciones distintas, y se ha observado que el significado del término «color» es una de las peores marañas de la ciencia. (Eco, 2009: 462)
}

El color en traducción no puede reducirse a pura materia y luz universales porque la sociedad de la cual traducimos y la sociedad a la cual traducimos construyen culturalmente sus propios colores. Como el símbolo o la imagen, el color en traducción es un fenómeno cultural que cada sociedad, cada civilización, vive y define de manera diferente según los contextos espacio-temporales. El único discurso posible sobre el color en traducción es de naturaleza social y antropológica. Cada cultura tiene sus colores favoritos, sus propias referencias plásticas que construyen estructuras simbólicas propias de complicidad, de placer o de rechazo. Cada cultura, cada civilización, cada época ha creado su propia simbología de 
colores y el traductor lee e interpreta los valores simbólicos otorgados a cada color para-traducirlos.

\begin{abstract}
La couleur est d'abord un fait de société. Il n'y a pas de vérité transculturelle de la couleur, comme voudraient nous le faire croire certains livres appuyés sur un savoir neurobiologique mal digéré ou - pire - versant dans une psychologie ésotérisante de pacotille. De tels livres malheureusement encombrent de manière néfaste la bibliographie sur le sujet. (Pastoureau, $2002: 5)$
\end{abstract}

La imagen y sus colores deben ser traducidos de una vez por todas. Una docencia universitaria de grado y de posgrado, con mención de calidad dedicada a formar futuros profesionales de la traducción, debería tener en cuenta de la necesidad pedagógica de iniciar a los estudiantes en la lectura e interpretación de las estructuras simbólicas de la imagen en traducción. Los diferentes sistemas simbólicos de cada cultura influyen enormemente en la lectura e interpretación de la imagen en traducción. Cada sistema simbólico deja profundas y numerosas huellas en la concepción y la definición de la imagen; en los usos de las formas y los colores simbólicos que resultan ser los de hoy pero no son los de ayer ni tampoco los de mañana; en los diferentes códigos semióticos y rituales simbólicos puestos en práctica en cada cultura; en el léxico de cada lengua; en el imaginario no sólo del texto sino también de la imagen que conforman el encargo de traducción.

\title{
4. LA IMAGEN EN TRADUCCIÓN: STUDIUM Y PUNCTUM
}

La imagen en traducción es un símbolo y no un signo. La excesiva importancia que nuestra cultura occidental ha otorgado a la palabra ha situado la imagen a remolque de la lengua y, por consiguiente, no sólo le ha otorgado un papel secundario sino que ha supuesto la equiparación de la imagen a un tipo de signo. iNada más erróneo! El traductor debe pensar la imagen no como un signo más sino como un elemento paratextual esencial en la institución de lo simbólico como principio de estrategia textual. La imagen no es más que una simbolización icónica. La imagen en traducción debe leerse e interpretarse de forma simbólica porque, a diferencia del signo (caracterizado siempre por su temporalidad), la dimensión espacial de la imagen hace de ella una especie de pantalla que invita al traductor a explorarla y franquearla en busca del placer de estar «dentro» de la imagen y no sólo «frente» a la imagen. Si el traductor no consigue experimentar la sensación del placer de estar «dentro» de la imagen, la traducción de los videojuegos, por 
ejemplo, está condenada al mayor de los fracasos. Leer e interpretar la imagen en la era digital, implica ser consciente de los diferentes tipos de relación que el espectador establece con la imagen en cada cultura.

L'Occident a appris à traiter les images comme des signes. Cette conception de l'image lui a permis, depuis la Renaissance, de s'approprier le monde. Mais elle l'empêche aussi aujourd'hui de comprendre les enjeux des nouvelles formes d'images. Tel est le véritable danger. [...] L'approche de l'image en termes de « signe » qui nous paraît pourtant « naturelle », fait obstacle à la compréhension des relations complexes que nous y nouons. [...] Les sémiologues qui s’intéressent à l'image se sont rendu compte que la catégorie de l'icône de Peirce, centrée sur la ressemblance, est insuffisante à rendre compte des pouvoirs de l'image. [...] La grande insuffisance de cette approche est d'utiliser un instrument qui n'est pas adapté à sa cible. L'instrument pensé par Peirce concerne en effet les relations internes entre le signifiant de l'image et son référent, alors que le problème principal posé par toute image concerne la relation que son spectateur noue avec elle. [...] La pensée de l'image comme « signe » est globalement dangereuse et insuffisante. Dangereuse parce qu'elle place l'image à la remorque tu mot; et insuffisante parce qu'elle ne rend pas compte de ses spécificités propres. [...] l'image envisagée comme signe souffre d'une irrémédiable infériorité par rapport au mot. (Tisseron, $2003: 29-30$ y 128-129)

La lectura e interpretación de la imagen en traducción debe tener siempre en cuenta las condiciones y los efectos de su recepción en las estructuras simbólicas de la cultura de llegada. Cultivar el sentido de la mirada del traductor resulta ser esencial a la hora de leer e interpretar la imagen. Sólo aquellos paratextos icónicos cultivados por la mirada lectora e interpretativa del traductor se convierten en imagen para traducir. Es la mirada del traductor la que hace que toda imagen se constituya en espacio que debe explorarse en un encargo de traducción. Es el sentido de la mirada del traductor lo que permite desvelar los imaginarios implícitos y explícitos.

Desde la noción de paratraducción como fundamento traductológico, la imagen puede ser considerada en traducción como un paratexto icónico cuya lectura e interpretación requieren de una cierta disciplina metodológica paratraductiva que cultive el sentido de la mirada del traductor. Dicha metodología paratraductiva, inspirada en la «regla estructural» establecida en su día por el propio Roland Barthes (1980), consistiría en que el traductor sea capaz de encontrar en toda imagen la copresencia de dos elementos discontinuos y heterogéneos que se producen entre el spectator y la imagen: el studium y el punctum. El studium es la palabra latina utilizada por Roland Barthes (1980: 48) para indicar ese movimiento de la mirada que parte del spectator (en nuestro caso, el traductor que deja de ver la imagen y empieza a mirar la imagen para-traducirla) y se dirige hacia la imagen. En cambio, el punctum indica el movimiento que parte de un detalle de la imagen y va dirigido hacia la mirada 
del spectator como una flecha que le hiere cual picadura puntuando la lectura y la interpretación de la imagen (Barthes, 1980: 49). En el primer movimiento, el studium, la lectura e interpretación de la mirada del paratraductor-spectator coincide con las intenciones generales creadas por el operator de la imagen ofrecida en su totalidad, mientras que el segundo movimiento, el punctum, desvía la mirada del paratraductorspectator para centrarla en un detalle que puede influir enormemente en la lectura e interpretación finales de la imagen.

\section{5. ¿«PICTOGRAMAS» PARA COMUNICARSE CON MUJERES EMBARAZADAS INMIGRANTES?}

Pictogramas para facilitar a comunicación coas mulleres embarazadas inmigrantes es el título de una publicación multilingüe editada en PDF por la Dirección de Asistencia Sanitaria del Servicio Gallego de Salud de la Xunta de Galicia para que los profesionales sanitarios (médicos y matronas) puedan comunicarse, sin necesidad de intérprete, con mujeres extranjeras embarazadas durante el seguimiento de los procesos de gestación que no entrañan dificultades. Se trata de un proyecto de traducción inversa verbo-icónica a 7 idiomas, financiado por el Ministerio de Sanidad y Política Social del Gobierno de España dentro del Plan de Calidad por el Sistema Nacional de Salud, y en el que han colaborado 9 traductores/as y 4 colaboradores/as. Los «pictogramas» de la publicación de la Xunta de Galicia pretenden convertirse en «traductores instantáneos» que ahorren los gastos de la presencia (física o virtual) de un intérprete

Tal y como ya he comentado en anteriores publicaciones editadas en red (Yuste Frías, 2010c y 2011e), la revisión y corrección de concepto, de estilo y tipográfica tanto de los textos originales (gallego y español) como de los siete textos traducidos de esta publicación de la Xunta de Galicia deja mucho que desear. Resulta difícil encontrar, en un espacio tan reducido de una sola página, tantas faltas de ortografía, errores gramaticales, solecismos, barbarismos y erratas en 9 idiomas.

Pero lo que me interesa destacar aquí es que todo el PDF de la Xunta de Galicia se fundamenta en la supuesta universalidad de la imagen. En efecto, la publicación consiste en una serie de frases breves ilustradas con unas imágenes dibujadas -que no «pictogramas»- que no cambian, ni de color de ni de forma, de una lengua a otra, de una cultura a otra. Las mismas imágenes se repiten en los 9 idiomas y en las 9 culturas. De hecho, el propio título de la portada anuncia que toda la publicación se basa en la imagen como lenguaje «universal» al equiparar 
los «dibujos» con «pictogramas». He aquí la portada (Imagen 1) con la que son introducidas y presentadas las 9 fichas que incluyen los «pictogramas» con sus respectivos textos en 9 idiomas: castellano, gallego, rumano, portugués, inglés, francés, árabe, chino y ruso. La imagen ocupa el mayor espacio de una portada donde el texto (el título) sólo ocupa dos líneas. El punctum de la imagen de la portada parte del detalle localizado en la combinación de colores existente entre los fetos y los rostros de las madres con rasgos físicos diferentes, y que «exagera», de manera algo simplista y bastante estereotipada, la paratraducción de la diversidad cultural de las mujeres embarazadas inmigrantes. Si se buscaba un estilo «naíf» en la publicación, hay que reconocer que no se podía haber hecho una representación más «pueril»a la diversidad cultural de la población inmigrante.

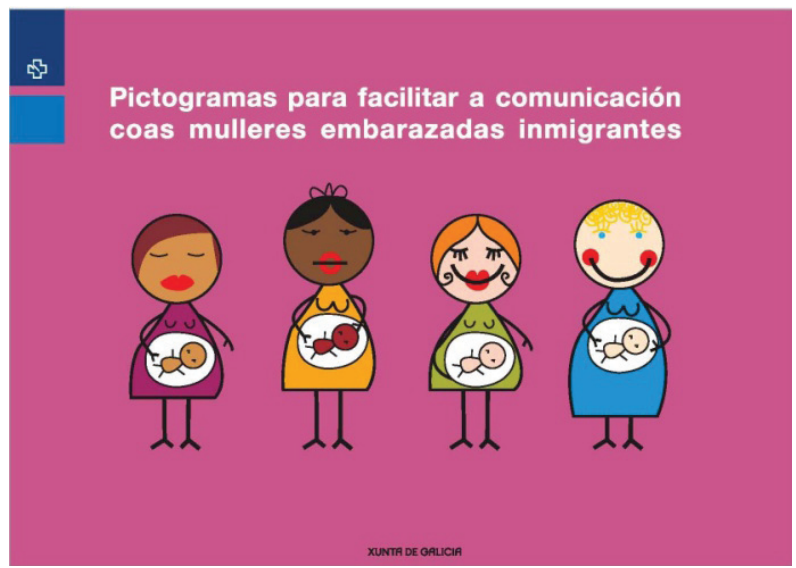

Imagem 1

Miren la versión española (Imagen 2) de los «pictogramas» y compárenla con las versiones francesa (Imagen 3) y árabe (Imagen 4), por ejemplo (por citar tan sólo dos traducciones verbo-icónicas inversas). Contemplen cómo no sólo no se ha cambiado ni una sola imagen, de una lengua a otra, de una cultura a otra, sino que ninguna imagen constituye, en realidad, «pictograma» alguno porque ninguna sigue las normas ISO. Muy al contrario, cada imagen revela una simbología y unos culturemas esencialmente occidentales. 


\begin{tabular}{|c|c|c|c|c|c|c|c|c|c|c|c|}
\hline \multirow{2}{*}{\multicolumn{4}{|c|}{$\begin{array}{c}\text { castelán } \\
\text { Soy la matrona }\end{array}$}} & \multirow{2}{*}{\multicolumn{2}{|c|}{\begin{tabular}{|c|c|} 
Si & No \\
\multicolumn{2}{|c|}{ Enero } \\
\end{tabular}}} & \multirow{2}{*}{$\begin{array}{l}\text { Dolor? } \\
\text { Febrero }\end{array}$} & \multirow{2}{*}{\multicolumn{2}{|c|}{$\begin{array}{c}\text { Manchas? } \\
\text { Marzo }\end{array}$}} & \multirow{2}{*}{$\begin{array}{c}\text { Vómitos? } \\
\text { Abril }\end{array}$} & \multicolumn{2}{|c|}{ castellano } \\
\hline & & & & & & & & & & Mayo & Junio \\
\hline \multicolumn{4}{|c|}{ Fecha última regla } & & & Agosto & Septi & & Octubre & Noviembre & Dicieml \\
\hline 1 & 2 & 3 & 4 & \multirow{3}{*}{\multicolumn{2}{|c|}{$\begin{array}{l}\text { Qué edad tienes? } \\
\text { Cuantos hijos tienes? }\end{array}$}} & \multicolumn{2}{|c|}{ Tiens alguna cesirea? } & \multirow{3}{*}{\multicolumn{2}{|c|}{$\begin{array}{c}\text { Alcrgica a } \\
\text { medicamentos? }\end{array}$}} & $\begin{array}{c}\text { Alguna } \\
\text { enfermedad? }\end{array}$ & $\begin{array}{l}\text { Has ido al médico } \\
\text { en el embarazo? }\end{array}$ \\
\hline 5 & 6 & 7 & 8 & & & \multirow{2}{*}{\multicolumn{2}{|c|}{ Cuando fué? }} & & & \multirow{2}{*}{$\begin{array}{c}\text { Alguna } \\
\text { operación? }\end{array}$} & \\
\hline 9 & 10 & 11 & 12 & & & & & & & & \\
\hline 13 & 14 & 15 & 16 & \multirow{3}{*}{\multicolumn{3}{|c|}{ 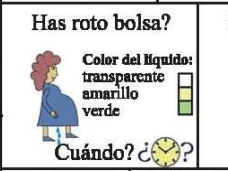 }} & \multirow{3}{*}{\multicolumn{2}{|c|}{$\begin{array}{l}\text { las sangrado? } \\
\text { Cuándo? ¿\&? ? }\end{array}$}} & \multirow{3}{*}{\multicolumn{2}{|c|}{ Tienes contracciones? }} & Te voy a explorar \\
\hline 17 & 18 & 19 & 20 & & & & & & & & \\
\hline 21 & 22 & 23 & 24 & & & & & & & & \\
\hline 25 & 26 & 27 & 28 & \multirow{2}{*}{\multicolumn{2}{|c|}{ Suero }} & \multirow{2}{*}{ 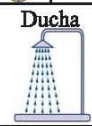 } & & C. & \multirow[t]{2}{*}{ Beber } & \multirow[t]{2}{*}{ Sentarte } & Caminar \\
\hline 29 & 30 & 31 & & & & & & & & & \\
\hline \multirow{2}{*}{\multicolumn{2}{|c|}{ Dia }} & \multirow{2}{*}{\multicolumn{2}{|c|}{ Noche }} & & $\begin{array}{l}\text { spira } \\
\text { ppacio }\end{array}$ & \multicolumn{2}{|c|}{ Sopla } & & & No empujes & $\begin{array}{c}\text { Tienes ganas de } \\
\text { empujar? }\end{array}$ \\
\hline & & & & & va bien & No te pr & cupes] & $\begin{array}{r}\text { Todo lo } \\
\text { es }\end{array}$ & \begin{tabular}{l|l|} 
nientes \\
nal
\end{tabular} & $\begin{array}{l}\text { El médico te } \\
\text { va a avudar }\end{array}$ & $\begin{array}{l}\text { Hay que hacerte } \\
\text { una cesárea }\end{array}$ \\
\hline
\end{tabular}

Imagem 2

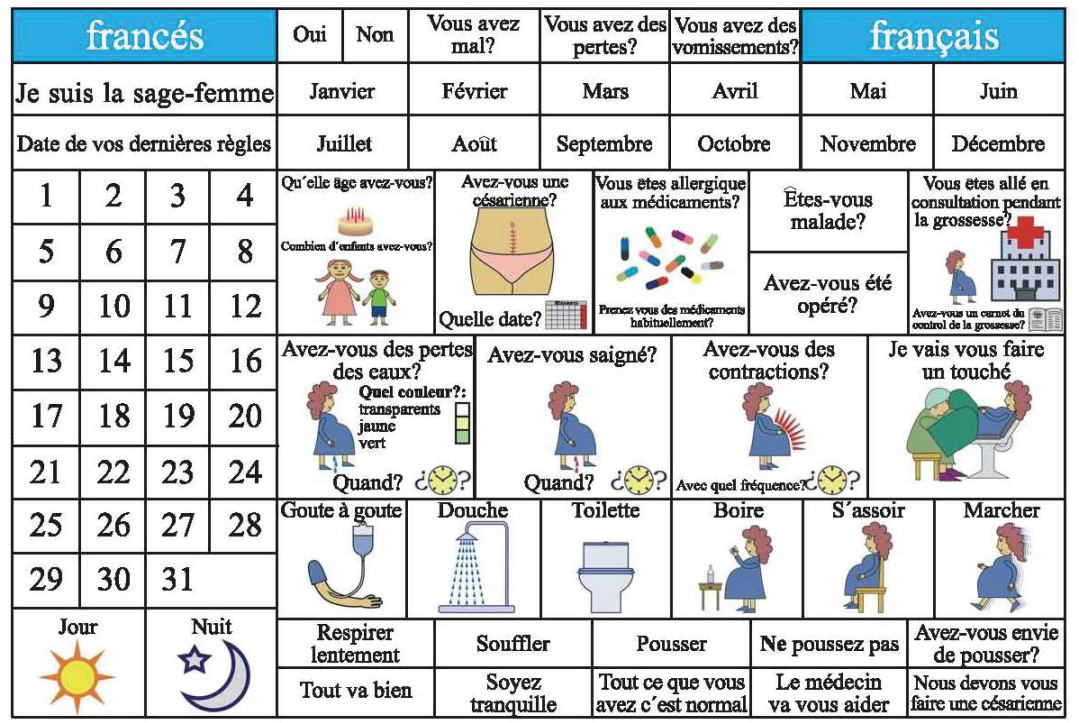

Imagem 3 


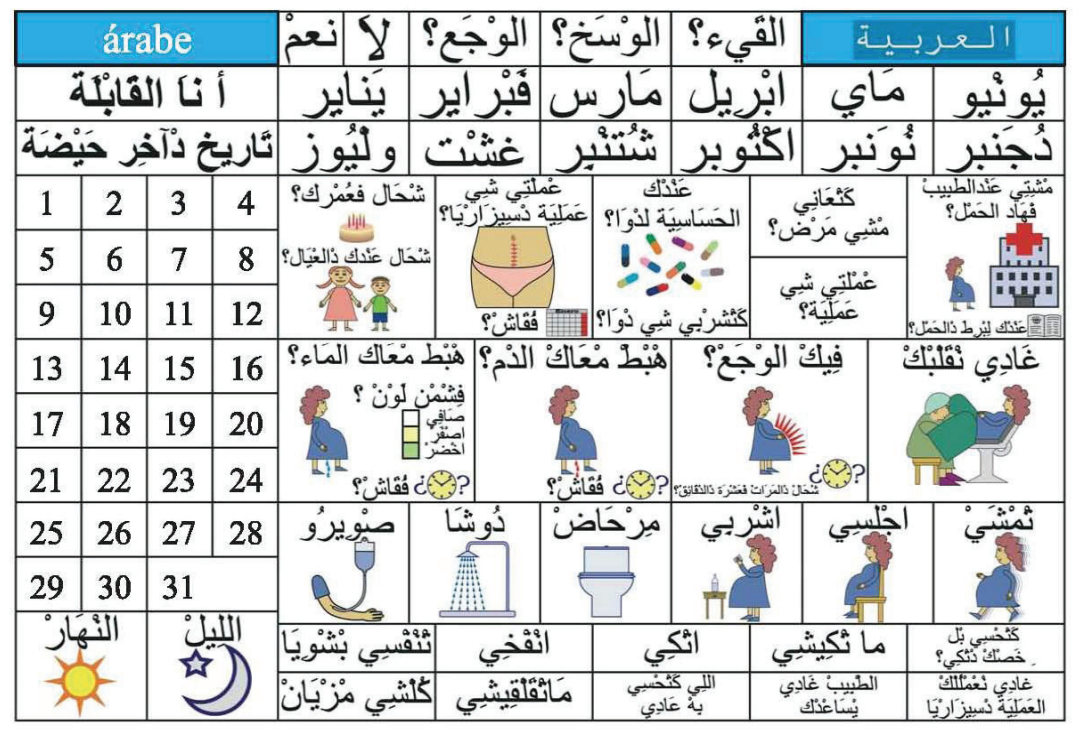

Imagem 4

Con el fin de no extenderme demasiado, tan sólo comentaré dos imágenes. El primer dibujo (que no «pictograma», insisto) que he elegido comentar es la imagen que se ha dibujado para simbolizar el centro hospitalario. Si bien es cierto que se trata de un hospital y no de un centro de la Cruz Roja, el símbolo de la cruz que se ha utilizado es el de la famosa Cruz Roja (Imágenes 5 y 6). Lo que me interpela como una flecha que me hiere cual picadura puntuando mi lectura e interpretación de la imagen en árabe (Imagen 7) es el punctum de seguir utilizando el mismo símbolo de la Cruz Roja. En efecto, en la versión árabe no se ha contemplado la posibilidad de cambiar la imagen de la cruz por la de la Media Luna Roja utilizada en los países musulmanes (Cf. Yuste Frías, 2011f).

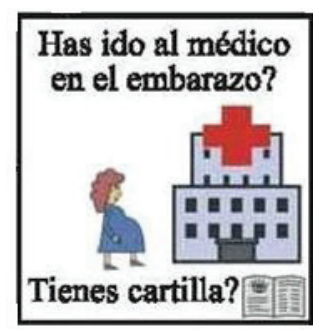

Imagen 5

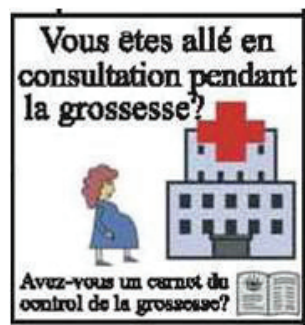

Imagen 6

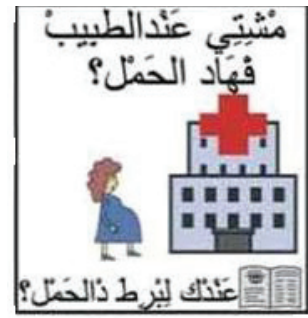

Imagen 7 
La segunda imagen que me gustaría comentar es la dibujada para representar uno de los momentos más delicados de la consulta ginecológica: la exploración. Sin querer entrar en el detalle lingüístico del texto de partida en el cual resulta de muy mala educación tutear a la paciente y dirigirse a ella con una dativo ético que no respeta en ningún momento su intimidad, llama poderosamente la atención la explicitación icónica del acto de exploración. El poco tacto de la frase «Te voy a explorar» (Imagen 8) aparece ilustrado con el punctum de la sonrisa medio esbozada en la cara de la paciente dibujada en la imagen. Nada más desconcertante que dicha sonrisa a la hora de leer e interpretar la imagen en las distintas lenguas y culturas. Por otra parte, la imagen de una mujer tumbada y reclinada con el médico sentado de frente a la zona vaginal para realizar la exploración no es una imagen «universal» porque puede prestarse a malas interpretaciones, ya que la exploración vaginal puede realizarse también con el médico examinador de pie (y no sentado), ya sea de frente o al costado de la camilla ginecológica.

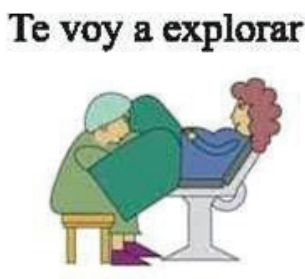

Imagen 8

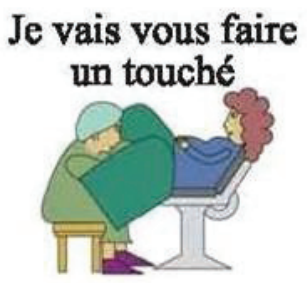

Imagen 9

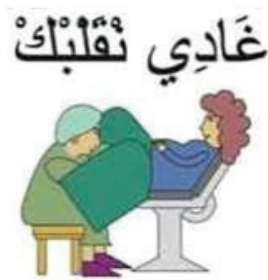

Imagen 10

Je vais vous faire un touché (Imagen 9) significa, literalmente en francés, «Le voy a hacer un tocado». «Una exploración» se escribe en francés así: un toucher. Es cierto que touché y toucher son dos palabras homófonas en francés pero no significan lo mismo para nada. Igual se pensó que así, cuando el médico o la matrona lo lea, al menos lo dirá bien y no pronunciará ninguna «r» al final porque igual no sabe leer francés. De todas formas, la frase «Te voy a explorar» junto a la imagen dibujada no puede traducirse sólo por una frase del tipo «Je vais vous faire un toucher vaginal» impresa en un papel por muy bien que se escriba la última palabra: la presencia del intérprete intercultural resulta imprescindible para saber en qué va a consistir esa «exploración/toucher». La interpretación en medio social implica siempre aspectos de comunicación no verbal (imágenes, símbolos, colores, olores, miradas, gestos, movimientos del cuerpo, silencios, etc.) cuya clave cultural no se encuentra en ningún papel por muchas imágenes que se dibujen en él. La Xunta de Galicia no ha pensado en el rechazo que una imagen como la dibujada (Imagen 10) puede provocar en la cultura musulmana. 
Pictogramas para facilitar a comunicación coas mulleres embarazadas inmigrantes es una publicación que ignora por completo la realidad profesional de la traducción/ interpretación en los servicios públicos. Una actividad que se lleva a cabo cada vez que un/a extranjero/a, inmigrante legal o ilegal, necesita los servicios de traducción y/o interpretación cuando intenta comunicarse con las distintas administraciones para hacer valer sus derechos en cada uno de los tres ámbitos imprescindibles para la construcción de una sociedad democrática y civilizada: sanidad, educación y justicia. De los tres ámbitos mencionados, la sanidad es el que mayor demanda los servicios de interpretación en medio social, muy por delante del ámbito judicial. También es el ámbito que más problemas culturales plantea. La buena marcha de los cuidados paliativos de un/a paciente depende en un porcentaje muy elevado de la labor de los intérpretes. Si el intérprete siempre interpreta à plus bault sens, cuando hace interpretación en el ámbito sanitario es consciente de que derrière chaque mot, il y a encore et toujours des mots qui évoquent des maux.

El intérprete en medio social es siempre una persona visible que asume su presencia consciente de su gran papel como principal actor social. Por muy buenas intenciones que haya tenido la Xunta de Galicia, debe hacerse a la idea de que jamás podrá prescindir del intérprete en los servicios públicos que gestiona y mucho menos convertirlo en simple «intérprete de papel». Una administración que pretende la invisibilidad del intérprete en medio social está condenada al mayor de los fracasos en política de inmigración. Mediar es mucho más que simplemente «traducir palabras» o entregar unos «pictogramas», que no son tales, acompañados de unos textos pésimamente redactados en las lenguas de los/as ciudadanos/as alófonos/as, porque ello no sólo dificulta enormemente la lectura sino también, y sobre todo, la comunicación.

Hay que ser consciente de que la percepción de lo que es salud y enfermedad varía de una cultura a otra, tanto como la propia representación icónica del cuerpo en cada una de ellas. No se puede tratar al sujeto migrante (ya sea inmigrante o emigrante) con estereotipos, idiosincrasias o tópicos culturales en imágenes dibujadas como las comentadas. El intérprete interpreta para personas, para identidades individuales y no para identidades culturales.

\section{6. ¿CARAS «NUEVAS» PARA TRADUCIR «NUEVAS»IDENTIDADES DE UN MISMO SABOR?}

Para terminar esta publicación propongo un último corpus para demostrar, con ejemplos prácticos y muy cotidianos, lo importante que resulta saber leer e 
interpretar la imagen para traducir. En este último ejemplo práctico, he recopilado distintas paratraducciones de la imagen que aparece en los estuches de una conocida marca de chocolate con el fin último de que el lector de esta publicación se pregunte por qué se han elegido distintas producciones paratextuales materiales en las distintas áreas culturales.

Para empezar, miren la imagen «original» construida en el paratexto formado por este estuche de la marca Kinder Schokolade (Imagen 11).

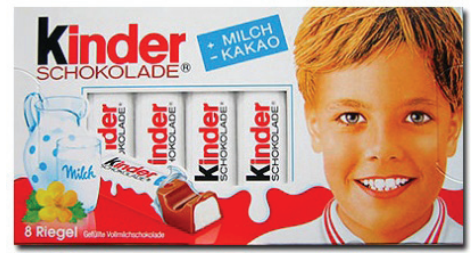

Imagen 11

El punctum principal de la lectura e interpretación de esta entidad iconotextual se sitúa alrededor del rostro del niño situado a la derecha del estuche donde se puede contemplar un niño de 7 ó 8 años, rubio aunque no mucho, bien peinado con las orejas y nuca despejadas, los dientes tan blanqueados como el blanco del lavado de su polo para mostrar una sonrisa tan artificial como falsa y las mejillas prominentes como recién salidas de una operación estética. Elementos todos que paratraducen la felicidad algo artificial de una infancia inconsciente, llena de salud y felicidad, alimentada a base de leche mañana, tarde y noche. El perfil de un niño primero de la clase y también preparado para cualquier actividad deportiva que se le cruce por el camino (las rayas rojas del cuello del polo resultan ser muy «deportivas»). En definitiva, el niño perfecto. Kinder en alemán quiere decir «niños». Estamos ante el chocolate con leche «alemán» que les gusta a todos los niños del mundo y que puede comerse en forma de barritas (tal y como aparecen en el estuche), de barra o de huevo sorpresa. Por mucho que los niños no alemanes se comen el chocolate Kinder sin preocuparse demasiado por el origen de su procedencia, lo cierto es que en Alemania se percibe como el chocolate del niño alemán, del deutsches Kind y, en el imaginario del consumidor alemán, comer chocolate Kinder es como comerse, en pequeñas dosis azucaradas, el alma alemana hasta lograr parecerse al modelo del niño que aparece en el estuche.

Pero el problema está en que el Kinder Schokolade no es alemán sino italiano. Sí, en efecto, Kinder es una marca italiana creada a finales de los años sesenta por el grupo Ferrero. ¿Por qué Ferrero decidió en su día bautizar su chocolate con el nombre de Kinder en lugar de Bambini?; ¿Por qué asociar todo un imaginario alemán a una marca de chocolate italiano? Chi lo sa? 
Lo que sí se sabe y se conoce es que, durante décadas, Ferrero introducía y presentaba en Francia su mismo producto de consumo, el chocolate (el texto), con una entidad iconotextual totalmente diferente en el estuche (el paratexto) paratraducir la imagen de un niño francés con ciertas diferencias con respecto al niño alemán. Miren y contemplen en estos estuches francófonos (Imágenes 12 y 13) cómo el niño francés iba vestido con un polo de otro color (o directamente una camisa y no un polo), tenía los ojos más azules que el niño alemán, y su pelo con melena ondulada en la frente era mucho más largo hasta el punto de que no sólo le cubría la nuca sino que le tapaba, completamente, las dos orejas, siguiendo la coupe cloclo puesta de moda por el artista francés Claude François.

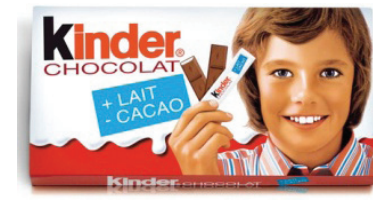

Imagen 12

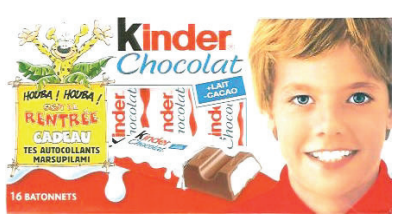

Imagen 13

Por otra parte, las diferentes paratraducciones de la imagen del niño realizadas en Alemania y Francia parecían decir que para comer Kinder Schokolade había que tener entre 7 y 8 años (Fig. 11) y para comer Kinder Chocolat entre 10 y 11 años (Imágenes 12 y 13). Conscientes de que las diferentes lecturas e interpretaciones que de la imagen del niño (el peritexto icónico del paratexto del estuche) podían hacerse en Francia con respecto a las hechas en Alemania, Ferrero decidió celebrar su trigésimo aniversario en Francia lanzando una campaña en busca no sólo del niño sino también de la niña (Féminisation du discours du politiquement correct oblige !) que podía simbolizar el Kinder Chocolat francés. Y así con el fin de paratraducir las diferentes identidades culturales que en un país como Francia pueden llegar a existir se imprimieron nuevas caras en los estuches. He aquí cuatro ejemplos de dos muestras (Imágenes 14 y 15) del safari fotográfico que pude hacer en aquella ocasión: 


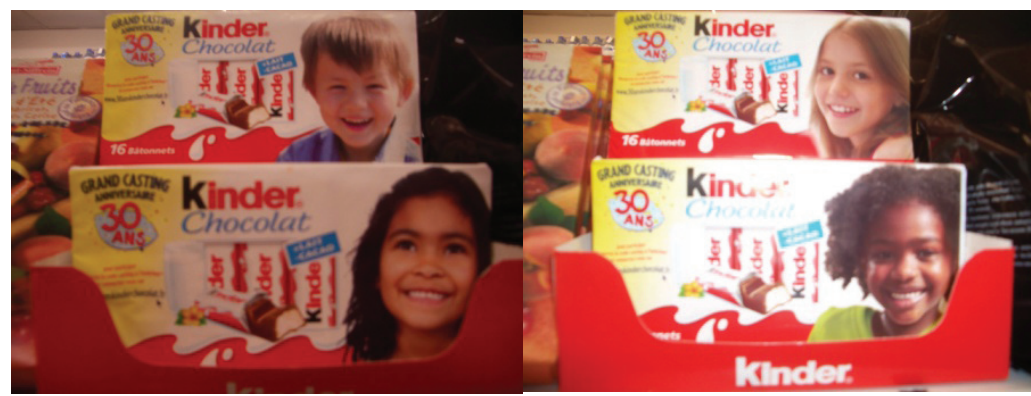

Imagen14

Imagen 15

La campaña publicitaria localizada en los estuches de Kinder Chocolat llevó a primer plano la lectura e interpretación de la realidad social para-traducir, con la imagen, las distintas identidades culturales de un país como Francia. Mestizaje en la paratraducción de la imagen: un niño blanco (con ojos achinados), una niña mulata, una niña blanca y una niña negra. Lejos queda la identidad monocultural, esencialmente germana, del niño alemán (Imagen 11). En plena zona de transición y de transacción ocupada por los estuches, asistimos a un magnífico ejemplo de localización del producto gracias a la paratraducción de la imagen que se adapta a los valores simbólicos de la cultura de llegada.

Tal y como ocurrió en Francia hace unos años, en España y Portugal también se acaba de lanzar la promoción de Conviértete en el niño Kinder (Imagen 16)/ Torna-te a criança Kinder (Imagen 17) en la cual un niño, tan rubio como el «original» pero vestido con una camisa a rayas que parece ser un mandilón, aparece en las dos versiones (española y portuguesa) del estuche de Kinder Chocolate en la página de inicio que encabeza la web de la promoción.

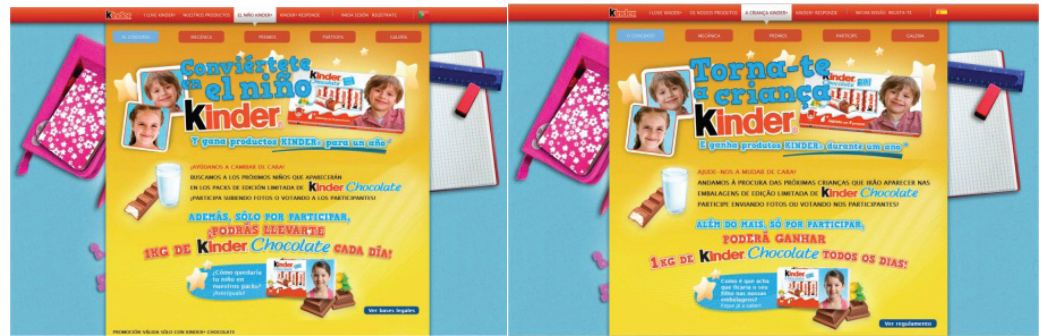

Imagen 16

Imagen 17

En el momento de escribir esta publicación ya hay hasta un niño y una niña finalistas en España y en Portugal, respectivamente. He aquí las fotos, supuestamente 
«naturales y originales», de «David de Valladolid» (Imagen 18) y «Lara de Lisboa» (Imagen 19).

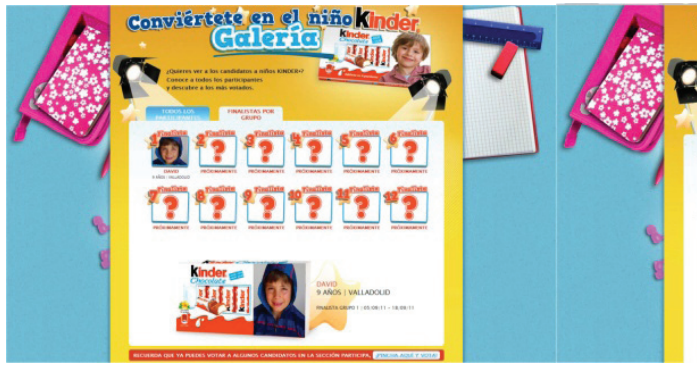

Imagen 18

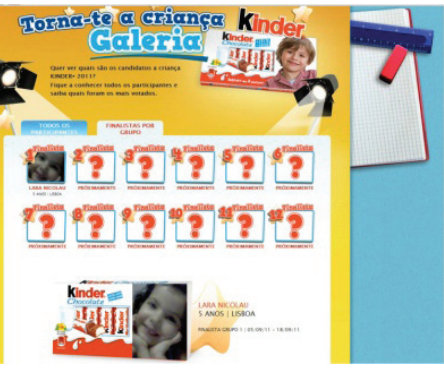

Imagen 19

Las eufonías de los nombres propios con sus ciudades respectivas, llegando a construir auténticas cartelas pictóricas poéticas con cierta rima (David de Valladolid_Lara de Lisboa), hace sospechar sobre la autenticidad de la construcción de la imagen. Puede que las fotos no sean originales, puede que todo sea un puro montaje publicitario, pero lo que nadie puede negar es que Ferrero quiere cuidar su imagen corporativa en el continente europeo y para ello utiliza la producción paratextual material más importante: el estuche que rodea, envuelve, acompaña, prolonga, introduce y presenta su producto. La misma campaña se realizó también en Gran Bretaña y una de las seis fotos elegidas fue la foto de Isla, una niña con síndrome de Down (Imagen 20). Ferrero invita a leer e interpretar la imagen para traducir la diferencia en un país altamente sensibilizado con este tema.

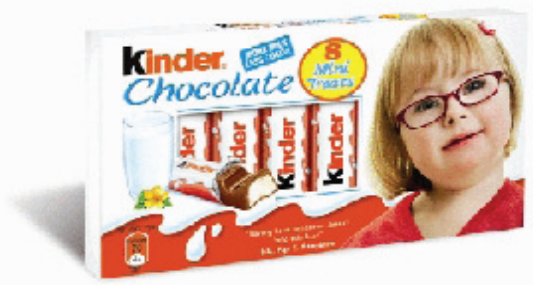

Imagen 20

Ahora bien, frente a todas estas paratraducciones de la imagen infantil materializadas en los estuches y adaptadas a la localización espacio-temporal de la cultura de llegada donde se quiere vender el chocolate Kinder, Ferrero también ha 
querido internacionalizar la imagen eligiendo el mismo niño «alemán» tanto para países europeos como para países de otros continentes. Me estoy refiriendo a la nueva manipulación que se ha hecho de la imagen del niño blanco germano rubio «original». La imagen internacional actual presenta a un niño que tiene los ojos azules, las mejillas algo sonrosadas, la frente despejada con ese peinado mucho más al estilo «alemán» que «francés», siempre con los dientes blancos pero, esta vez, con algún que otro colmillo sobresaliente y vestido con polo naranja sin olvidar nunca ponerlo mirando siempre al frente, nunca de lado o de perfil (Imagen 21).

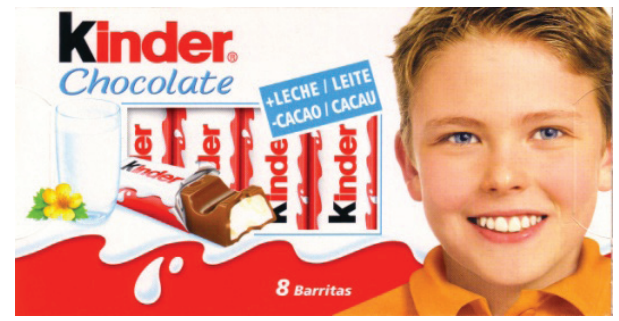

Imagen 21

A la hora de exportar al mundo el chocolate Kinder, Ferrero ha querido ahorrar costes al imprimir una misma imagen para todo el mundo. Se ha optado por hacer prevalecer el imaginario de la monopertenencia cultural germana frente a la diversidad cultural imaginada el tiempo que dura una campaña de promoción realizada para contentar la mirada crítica de algunos europeos. Por mucho que el producto que se exporta no sea alemán sino de origen italiano, parece que en tiempos de crisis, la paratraducción icónica de la Deutsch Qualität en publicidad internacional se erige como valor simbólico para asegurar las ventas globales (Yuste Frías, 2011g).

\section{CONCLUSIONES}

El uso del ordenador como medio universal de información y comunicación ha ampliado enormemente el papel de la imagen en la actividad traductora. Al vivir rodeados de pantallas, la cibercultura nos obliga a los traductores a pasar todo el santo día (y gran parte de la noche), delante de todo tipo de pantallas (ordenadores, televisores, teléfonos, tabletas y pizarras digitales) que difunden información, reflejan culturas, manifiestan comportamientos, manipulan nuestras ideas y sensaciones, pero, sobre todo, nos abren los ojos y los oídos a otras lenguas, a otros valores, a otras maneras de ver el mundo gracias a la imagen. 
La manipulación de la imagen, conlleva no sólo implicaciones simbólicas, sino también, ideológicas, políticas, sociales y culturales. La noción de paratraducción ayuda al traductor a ser consciente de que toda manipulación icónica puede o bien empobrecer o bien enriquecer la mayoría de los contenidos traducidos. El concepto de paratraducción otorga a la imagen y a todo el aspecto visual de los paratextos la importancia que tienen en la construcción de sentido simbólico en traducción, sin olvidar nunca que tanto la imagen como sus colores no son universales. La noción de paratraducción permite cultivar el sentido de la mirada del traductor, ya que es el sentido de la mirada del traductor lo que permite desvelar los imaginarios implícitos y explícitos en la lectura e interpretación de la imagen.

Desde la noción de paratraducción como fundamento traductológico, la imagen puede ser considerada en traducción como un paratexto icónico cuya lectura e interpretación simbólicas requieren de una cierta disciplina metodológica paratraductiva a la hora de cultivar el sentido de la mirada del traductor. Dicha metodología paratraductiva consistiría en que el traductor sea capaz de encontrar en toda imagen la co-presencia de dos elementos discontinuos y heterogéneos que se producen entre el spectator y la imagen considerada como símbolo: el studium y el punctum.

A través de dos corpus diferentes, por un lado, las imágenes dibujadas de los «pictogramas» de la Xunta de Galicia y, por otro, las «nuevas caras» de los estuches de Kinder Chocolate, hemos comprobado que el mínimo detalle de una imagen puede llevar a diferentes lecturas e interpretaciones según haya sido la construcción paratextual finalmente editada en la lengua y cultura de llegada. Por mucho que se traduzca bien los textos, si en la edición final de la información sanitaria que va dirigida a un público alófono (Pictogramas de la Xunta) o en la presentación final del producto de consumo que se quiere exportar (Kinder Chocolate), los paratextos icónicos no han pasado por la mirada del traductor, sujeto que traduce y primer agente paratraductor, la calidad de comunicación puede sufrir graves problemas de lectura e interpretación cuando el lector-espectador final empiece a mirar lo que hasta entonces sólo veía.

\section{REFERÊNCIAS BIBLIOGRÁFICAS}

BARTHES, R. (1980) La chambre claire. Note sur la photograpbie, París: Gallimard, Seuil (col. Cahiers du Cinéma).

GENETTE, G. (1987) Senils, Paris: Seuil. 
ECO, U. (2009) Decir casi lo mismo (tít. orig.: Dire quasi la stessa cosa [2003]; trad. esp. de Helena Lozano Miralles), Barcelona: Debolsillo.

PASTOUREAU, M. (2002) Bleu. Histoire d'une couleur, Paris: Seuil, col. Points n. ${ }^{\circ} 1028$.

TISSERON, S. $(2003)^{2}$ Le bonbeur dans l'image, Paris: les Empêcheurs de penser en rond / Le Seuil.

YUSTE FRÍAS, J. (2005) «Desconstrucción, traducción y paratraducción en la era digital», en Yuste Frías, J. y A. Álvarez Lugrís [eds.], (2005) Estudios sobre traducción: teoría, didáctica, profesión, Vigo: Servizo de Publicacións da Universidade de Vigo, col. T\&P, n. ${ }^{\circ}$ 1, pp. 59-82. Capítulo de libro disponible en la web del autor: <http://www. joseyustefrias.com/docu/publicaciones/JoseYusteFrias\%202005c.pdf $>$

- (2008a) «Pensar en traducir la imagen en publicidad: el sentido de la mirada» PLP Pensar La Publicidad. Revista Internacional de Investigaciones Publicitarias, vol. II, n. ${ }^{\circ} 1$ (2008): 141-170. Artículo impreso disponible en la web del autor <http://www. joseyustefrias.com/docu/publicaciones/JoseYusteFrias2008.pdf $>$ y en la web de la revista $<\underline{\text { http://revistas.ucm.es/inf/18878598/articulos/PEPU0808120141A.PDF }>~}$ . (2008b) «Para-traducir Carrefour (1 a parte)», en Yuste FríAs, J. [dir.] Zig-Zag. El primer programa Web-TV dedicado a la traducción, episodio n. ${ }^{\circ} 2$ editado en red el 16/06/2008, [en red], Vigo: T\&P_UVigo-TV, < http://tv.uvigo.es/video/27034 >. Presentación de esta producción audiovisual T\&P disponible en la web del autor: < http://www. joseyustefrias.com/index.php/publicaciones/audiovisuales/42-videos/109-episodiono-2-de-zig-zag-para-traducir-carrefour-1o-parte.html $>$ Presentación del programa Web-TV Zig-Zag también disponible en la web del autor: < http://www.joseyustefrias. com/index.php/web-tv/zig-zag.html>

. (2009a) «Paratraduction: le concept-clé de l'École de Vigo», en Yuste FríAs, J. [dir.] II Coloquio Internacional de Vigo sobre paratraducción (Primera Parte), [en red], Vigo: T\&P_UVigo-TV. Editada en red y almacenada en el repositorio de la web de UVigoTV $<$ http://tv.uvigo.es/video/25363 > , esta producción audiovisual del Grupo T\&P constituye la $4^{\text {a }}$ conferencia del II Coloquio Internacional de Vigo sobre paratraducción (Primera Parte), celebrado del 3 al 5 junio de 2009 en la Facultade de Filoloxía e Tradución de la Universidade de Vigo. Un acto académico dirigido, organizado y editado en red por José Yuste Frías : < http://tv.uvigo.es/es/serial/558.html > . En la web del autor existe una presentación detallada de esta publicación audiovisual: < $<$ ttp://www. joseyustefrias.com/index.php/publicaciones/audiovisuales/200-paratraduction-leconcept-cle-de-lecole-de-vigo.html>

. (2009b) «Débat sur "Paratraduction: le concept-clé de l’École de Vigo "», en Yuste FRíAS, J. [dir.] II Coloquio Internacional de Vigo sobre paratraducción (Primera Parte), [en red], Vigo: T\&P_UVigo-TV. Editada en red y almacenada en el repositorio de la web de UVigo-TV $<$ http://tv.uvigo.es/video/25362 $>$, esta producción audiovisual del Grupo T\&P constituye la grabación del debate que tuvo lugar tras la $4^{\mathrm{a}}$ conferencia del II Coloquio Internacional de Vigo sobre paratraducción (Primera Parte), celebrado del 3 al 5 
junio de 2009 en la Facultade de Filoloxía e Tradución de la Universidade de Vigo. Un acto académico dirigido, organizado y editado en red por José Yuste Frías :

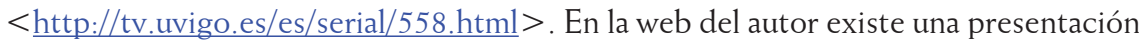
detallada de esta publicación audiovisual: <http://www.joseyustefrias.com/index. $\mathrm{php/publicaciones/audiovisuales/201-debate-sobre-1paratraduction-le-concept-cle-}$ de-lecole-de-vigor.html> . (2010a) «Para-traducir Carrefour (2 a parte)», en Yuste FríAS, J. [dir.] Zig-Zag. El primer programa Web-TV dedicado a la traducción, episodio n. ${ }^{\circ} 4$ editado en red el 09/04/2010, [en red], Vigo: T\&P_UVigo-TV, < http://tv.uvigo.es/video/27042>. Presentación de esta producción audiovisual T\&P disponible en la web del autor: < http://www. joseyustefrias.com/index.php/publicaciones/audiovisuales/42-videos/139-episodiono-4-de-zig-zag-para-traducir-carrefour-2o-parte.html > Presentación del programa Web-TV Zig-Zag también disponible en la web del autor: < http://www.joseyustefrias. com/index.php/web-tv/zig-zag.html>

. (2010b) «Au seuil de la traduction : la paratraduction», en NAAIJKENS, T. [ed.] Event or Incident. Événement ou Incident. On the Role of Translation in the Dynamics of Cultural Exchange. Du rôle des traductions dans les processus d'échanges culturels, Bern, Berlin, Bruxelles, Frankfurt am Main, New York, Oxford, Wien: Peter Lang, col. Genèses de Textes-Textgenesen (Françoise Lartillot [dir.]), vol. 3, pp. 287-316. Publicación disponible en la web del autor con información detallada del libro en el que fue editado el capítulo: $<\underline{\text { http:// }}$ www.joseyustefrias.com/index.php/publicaciones/prueba-libros/64-informaciondetallada/174-au-seuil-de-la-traduction-la-paratraduction.html $>$

. (2010c) «Intérpretes de papel para mujeres embarazadas inmigrantes», Blog de Yuste. On y sème à tout vent, [en red], 24/02/2010, Vigo: Blogs de Investigación T\&P < http:// joseyustefrias.com/index.php/blog/item/interpretes-de-papel-para-mujeresembarazadas-inmigrantes.html >

. (2011a) «Traduire l'image dans les albums d'Astérix. À la recherche du pouce perdu en Hispanie» en Richet, B. [ed.] Le tour du monde d'Astérix, París: Presses Sorbonne Nouvelle, pp. 255-271. Publicación disponible en la web del autor con información detallada del libro en el que fue editado el capítulo: $<$ http://www.joseyustefrias.com/ index.php/publicaciones/capitulos-de-libro/208-traduire-limage-dans-les-albumsdasterix.html $>$

. (2011b) «La imagen del logotipo Carrefour I: las flechas», Blog de Yuste. On y sème à tout vent, [en red], 28/01/2011, Vigo: Blogs de Investigación T\&P < http://www. joseyustefrias.com/index.php/blog/item/la-imagen-del-logotipo-carrefour-1-las$\underline{\text { flechas.html }>~}$

. (2011c) «La imagen del logotipo Carrefour II: los colores», Blog de Yuste. On y sème à tout vent, [en red], 4/02/2011, Vigo: Blogs de Investigación T\&P < http://www. joseyustefrias.com/index.php/blog/item/la-imagen-del-logotipo-carrefour-2-loscolores.html> 
. (2011d) «La imagen del logotipo Carrefour III: la letra C», Blog de Yuste. On y sème à tout vent, [en red], 11/02/2011, Vigo: Blogs de Investigación T\&P < http://www. joseyustefrias.com/index.php/blog/item/la-imagen-del-logotipo-carrefour-3-laletra-c.html $>$

. (2011e) «Mujer embarazada inmigrante busca intérprete que no sea de papel», Decimoduinta Pildora T\&P, [en red], 12/04/2011, Vigo: T\&P_UVigo-TV < http:// www.joseyustefrias.com/index.php/web-tv/pildorastyp/57-pildoras/184-mujerembarazada-inmigrante-busca-interprete-que-no-sea-de-papel.html $>$ Contribución del autor al $4^{\circ}$ Congreso Internacional Traducción e Interpretación en los Servicios Públicos, organizado por el Grupo de Investigación FISTISPos de la Universidad de Alcalá. . (2011f) «La leyenda vienesa del croissant o cómo comerse al Otro», Blog de Yuste. On y sème à tout vent, [en red], 30/09/2011, Vigo: Blogs de Investigación T\&P < http://www. joseyustefrias.com/index.php/blog/item/la-leyenda-vienesa-del-croissant.html > . (2011g) «Hablar alemán para traducir calidad», Blog de Yuste. On y sème à tout vent, [en red], 21/10/2011, Vigo: Blogs de Investigación T\&P < http://www.joseyustefrias. com/index.php/blog/item/hablar-aleman-para-traducir-calidad.html $>$

Recebido: 19/10/2011

Aceito: 04/11/2011 